\title{
Rapid identification of shallow inundation for mosquito disease mitigation using drone-derived multispectral imagery
}

\author{
Tasya Vadya Sarira, ${ }^{1}$ Kenneth Clarke, ${ }^{1}$ Philip Weinstein, ${ }^{1}$ Lian Pin Koh, ${ }^{1,2}$ Megan Lewis ${ }^{1}$ \\ ${ }^{1}$ School of Biological Sciences, The University of Adelaide, Adelaide, Australia; ${ }^{2}$ Department of Biological \\ Sciences, National University of Singapore, Singapore
}

\begin{abstract}
Mosquito breeding habitat identification often relies on slow, labour-intensive and expensive ground surveys. With advances in remote sensing and autonomous flight technologies, we endeavoured to accelerate this detection by assessing the effectiveness of a drone multispectral imaging system to determine areas of shallow inundation in an intertidal saltmarsh in South Australia. Through laboratory experiments, we characterised Near-Infrared (NIR) reflectance responses to water depth and vegetation cover, and established a reflectance threshold for mapping water sufficiently deep for potential mosquito breeding. We then applied this threshold to field-acquired drone imagery and used simultaneous in-situ observations to assess its mapping accuracy. A NIR reflectance threshold of 0.2 combined with a vegetation mask
\end{abstract}

Correspondence: Tasya Vadya Sarira, School of Biological Sciences, The University of Adelaide, Adelaide, SA 5005, Australia

Tel.: +61 883132796

Fax: +61883134362

E-mail: tasya.sarira@adelaide.edu.au

Key words: Drones; multispectral; remote sensing; habitat identification; mosquitoes.

Acknowledgments: The authors want to thank the School of Biological Sciences of The University of Adelaide for project funding, Ramesh Raja Segaran from the Unmanned Research Aircraft Facility for the acquisition and processing of drone imagery and Trevor Garnett from The Plant Accelerator for hosting our laboratory trials. We also like to thank Sreekar Rachakonda for statistical advice, Andrew Vickers and Michaela Hobby from SA Health and the District Council of Barunga West for discussions on mosquito mitigation efforts in South Australia.

Conference presentation: Part of this paper was presented at the 17th Spatial Information Day, 11 August 2017, Adelaide, South Australia.

Conflict of interests: The authors declare no potential conflict of interests.

Received for publication: 18 December 2019.

Accepted for publication: 30 March 2020.

(c) Copyright: the Author(s), 2020

Licensee PAGEPress, Italy

Geospatial Health 2020; 15:851

doi:10.4081/gh.2020.851

This article is distributed under the terms of the Creative Commons Attribution Noncommercial License (CC BY-NC 4.0) which permits any noncommercial use, distribution, and reproduction in any medium, provided the original author(s) and source are credited. derived from Normalised Difference Vegetation Index (NDVI) resulted in a mapping accuracy of $80.3 \%$ with a Cohen's Kappa of 0.5 , with confusion between vegetation and shallow water depths $(<10 \mathrm{~cm})$ appearing to be major causes of error. This high degree of mapping accuracy was achieved with affordable drone equipment, and commercially available sensors and Geographic Information Systems (GIS) software, demonstrating the efficiency of such an approach to identify shallow inundation likely to be suitable for mosquito breeding.

\section{Introduction}

Mosquito-borne diseases, a subgroup of and hereafter referred to as arboviruses, are an increasing threat to global public health. In addition to the loss of lives, arboviruses directly or indirectly contribute to significant disease burden through medical costs as well as through the reduction of human productivity (Mackenzie and Smith, 1996). Nevertheless, in time, infections are expected to increase due to faster development of larvae and shorter viral incubation times within varying mosquito species from the effects of climate change (Bi et al., 2009; Russell, 1998). Increased enroachment into mosquito habitat, particularly wetlands through recreation or development further increases the risk of viral transmission (Bi et al., 2009; Russell, 1998).

In South Australia, larvicides are utilised in mosquito control programs, which breaks larval life-cycles and prevents larvae from pupating into adults (Government of South Australia, 2006). Typically, this requires the targeting of suitable breeding habitats i.e. pools of shallow standing waters often among low vegetation that are difficult to access, through time consuming, labour intensive and expensive ground surveys organised by local public health agencies (Dale et al., 1986).

Satellite imagery has commonly been used to identify breeding habitats, particularly towards malaria mitigation efforts in developing cities (Clennon et al., 2010; Dambach et al., 2012; Hassan et al., 2013; Hugh-Jones, 1989). For these studies, moderate spatial resolution imagery $(10-30 \mathrm{~m})$ were used, which, although suitable for broad scale regional studies, may fail to identify small or shallow mosquito breeding pools in localised areas.

The low cost of drones (<AUD\$1000), combined with their flexibility to be deployed rapidly and acquire real time high-resolution imagery, may therefore be a better remote sensing alternative (Bergquist and Amer, 2019). The ability for users to execute autonomous flights at lower altitudes means that drones can be used to determine potential breeding sites in inaccessible terrain at higher resolutions and at more appropriate times. This improves survey efficiency, as demonstrated by Hardy et al. (2017) where potential breeding sites were identified in rice paddies, ponds, as well as urban and peri-urban landscapes in Zanzibar using drone- 
derived colour orthomosaics of $7 \mathrm{~cm}$ pixels. Multispectral sensors that record imagery at various wavelengths have been frequently used in drone remote sensing applications, such as environmental monitoring and precision agriculture (e.g. Fernandez-Guisuraga et al., 2018; Paredes et al., 2017). In principle, through the identification of distinctive spectral properties, features such as pools of water can be differentiated from other land classes (Paine and Kiser, 2003). For example, Chabot et al. (2018) utilised the spectral differences between water and vegetation to delineate abovewater vegetation from submerged features using a drone-derived multispectral image, where vegetation is indicated by a higher reflectance than water features.

While Carrasco-Escobar et al. (2019) highlights the capability of multispectral sensor systems to positively detect the presence of larvae in water bodies at $2 \mathrm{~cm}$ pixel resolutions, there has been no reported studies that determines the depth at which multispectral sensors are able to accurately discern water features from other land classes. This paper reports research which aimed to determine the minimum depth at which multispectral sensors are able to accurately detect water, through, firstly, the characterisation of NIR reflectance of water depth and vegetation cover in a controlled setting, and then applying these findings in a typical coastal saltmarsh to rapidly map potential breeding habitats using multispectral drone imagery.

\section{Methods}

Laboratory simulations were first implemented to explore the relationship of water depth and vegetation cover, typical of a South Australian saltmarsh on rich organic substrate, to NIR reflectance (Rowbottom et al., 2017). The findings subsequently contributed towards analyses of multispectral drone imagery that attempted to map potential breeding areas of focal saltmarsh mosquito species, Aedes vigilax and Aedes camptorhynchus, known to be vectors of the Ross River Virus (RRV) in Australia (Johnston et al., 2014). Assessment of the mapping accuracy was based on in situ observations collected at the time of drone image acquisition.

\section{Laboratory trials}

Ross River Virus cases have been associated with coastal or inland saltmarsh habitat, with epidemics commonly occurring following inundation from tides or rain (Mackenzie and Smith, 1996; Russell, 1998). For our laboratory trial, we explored the NIR response of key habitat components, shallow water inundation and vegetation cover, as well as their combined effects on spectral response. Water absorbs NIR radiation more strongly than organic substrate or vegetation, and would be represented in the NIR imagery as darker pixels of lower relative reflectance (Goward et al., 1994). To simulate the organic-rich soils in coastal saltmarsh, Pinus radiata bark was chosen as the substrate for the experiments as it is dark-coloured and rich in humic materials such as lignin and cellulose, providing a good spectral analogue to the organic-rich soils in saltmarshes.

The multispectral sensor used was the five-sensor MicaSense RedEdge (MicaSense, 2015), covering the blue (centre wavelength at $475 \mathrm{~nm})$, green $(560 \mathrm{~nm})$, red $(668 \mathrm{~nm})$, red edge $(717 \mathrm{~nm})$ and NIR $(840 \mathrm{~nm})$ wavelengths. It captures 1280 x 960-pixel images, at a ground sample distance of $8.2 \mathrm{~cm}$ per pixel at $120 \mathrm{~m}$ Above Ground Level (AGL).

For each trial, the experimental setup involved one set of three inundated rectangular buckets ( 57 x 32 × $38 \mathrm{~cm})$, with dark organic substrate set at the bottom to simulate shallow breeding pools, and another set of three non-inundated buckets as the control, with damp organic substrate that simulated pool edges. The sensor was positioned nadir to each bucket at a height of $1.2 \mathrm{~m} \mathrm{AGL}$, imaging the entire surface area of the simulated environments within each inundated and non-inundated bucket. The sensor was calibrated before each experiment using a calibration panel of $98 \%$ reflectance (MicaSense, 2015). For the water depth trial, the water depth in the inundated buckets (hereafter referred to as treatments) was varied at $5 \mathrm{~cm}, 10 \mathrm{~cm}, 15 \mathrm{~cm}, 20 \mathrm{~cm}$ and $25 \mathrm{~cm}$, and three NIR images were acquired for both the inundated and non-inundated treatments at each water depth, totalling 15 images for this trial. For the vegetation cover trial, a frame of bamboo leaves with varying covers i.e. approximately $10 \%, 20 \%, 50 \%, 70 \%$ and $90 \%$ was placed above the buckets themselves, with water level in the inundated treatments fixed at $15 \mathrm{~cm}$. Bamboo leaves were used for they were a readily available analogue for photosynthesising wetland vegetation. The leaves were obtained shortly prior to the commencement of the trial and kept hydrated such that their photosynthetic capacities were conserved. Three NIR images were captured for each vegetation cover, for both the inundated and non-inundated treatments totalling 15 images for this trial.

The Digital Numbers (DNs) from the NIR imagery were then extracted from the appropriate areas of each image to eliminate the bucket edges from analysis. This was done through the manual digitisation of shapefiles for each non-georegistered image in ArcMap 10.3.1 (ESRI, 2015). The DNs were then converted to percentage reflectances to control for variable lighting conditions at the time of image capture using a linear calibration equation based on the mean DN values of the calibration panel $(98 \%$ reflectance) as well as dark images ( $0 \%$ reflectance) (Smith and Milton, 1999) (see Appendix). We then obtained the mean percentage reflectances of all 30 images and used a two-factor ANOVA with replication to assess for differences between treatments (inundated or non-inundated), variables (water depth and vegetation cover) or potential interactions.

\section{Field Trials}

The field study was conducted on $6^{\text {th }}$ September 2016 in an intertidal coastal saltmarsh located near Port Broughton in South Australia $\left(33.58^{\circ} \mathrm{S}, 137.94^{\circ} \mathrm{E}\right), 170 \mathrm{~km}$ north-west of Adelaide. The region is temperate, with a mean annual rainfall of $374 \mathrm{~mm}$ (Bureau of Meteorology, 2019), and dominated by low open samphire (Tecticornia spp.) of various leaf colours on grey clay, organic-rich soils. It was generally sunny with occasional sparse cirrus or stratus clouds, and an ambient temperature of $22^{\circ} \mathrm{C}$. High tides and rain the previous day resulted in the presence of many temporary pools in the area.

A ground survey was conducted to provide the basis for an accuracy assessment of the drone image mapping. The area assessed was approximately $1.7 \mathrm{ha}$, divided into six quadrats of approximately 50 x 65 m (Figure 1). Stratified directed sampling was implemented where we determined habitat cover types beforehand and then identified a minimum of three samples of each cover type per quadrat if found. These were i) water; ii) vegetation; iii 3) soils and iv) algae, divided into nine sub-classes: open water; water under dead vegetation; water under vegetation; algae under water; live vegetation; dead vegetation; wet algae; dry algae and bare soil (Table 1). This was done such that there was a good distribution of sample cover types across the study area. 
Seventy-one homogenous plots were sampled, each covering approximately $710 \mathrm{~cm}^{2}$ (30 $\mathrm{cm}$ diameter). Recorded at each plot were the dominant cover type, depths of water if present, colour photographs at nadir, and central plot GPS coordinates with a differential GPS (dGPS) of horizontal accuracy better than $\pm 5 \mathrm{~cm}$.

Multispectral imagery of the field site was obtained within an hour and a half of solar noon to minimise shadows using a 3DR Iris + mounted with the MicaSense sensor at $40 \mathrm{~m}$ AGL. Sixteen ground control points (GCPs) were placed within the study area for subsequent georegistration of imagery, and their coordinates recorded with a dGPS. The GCPs were marked with reflective tape for them to be subsequently located in the multispectral imagery.

\section{Image Processing}

Image processing involved the production of a georegistered 2.7 ha mosaic from 85 images of approximately $2.7 \mathrm{~cm} /$ pixel resolution, using Pix4DMapper software (pix4d.com). This was followed by the analyses of the composite NIR and NDVI imagery in ArcMap 10.3.1.

Shallow inundation was defined when the NIR reflectance in the mosaic, as well as the mean value of pixels within each sample plot was less than 0.2 based on the results from the laboratory trials. NIR reflectances equal and greater than 0.2 were considered to be non-inundated, assuming that the NIR spectral response at 1.2 $\mathrm{m} \mathrm{AGL}$ as in the laboratory trials, and at $40 \mathrm{~m}$ AGL as in the field trials are the same. Vegetation on the other hand, was defined through a composite NDVI mask, when the NDVI was equal or greater than 0.4 . This value was the minimum NDVI obtained from the composite imagery found to be vegetation on the ground. Potential areas for mosquito breeding i.e. shallow inundation with no overhanging vegetation were therefore defined by NIR reflectance lower than 0.2 and NDVI lower than 0.4 . This concurrently reduced the confusion between 'water' and 'vegetation'
Table 1. Cover types and sub-classes identified during the field survey. Cover type 'water' is considered as inundated, while cover types 'vegetation', 'algae' and 'soil' are considered non-inundated.

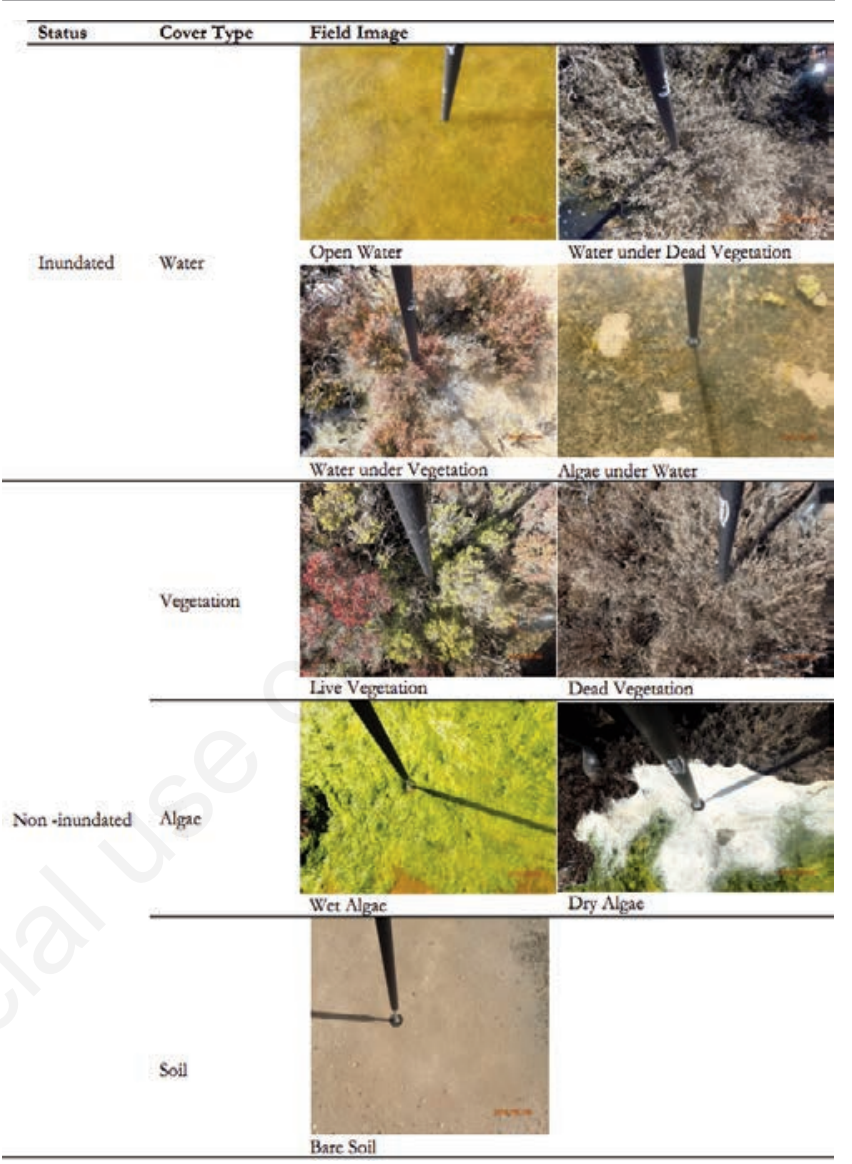

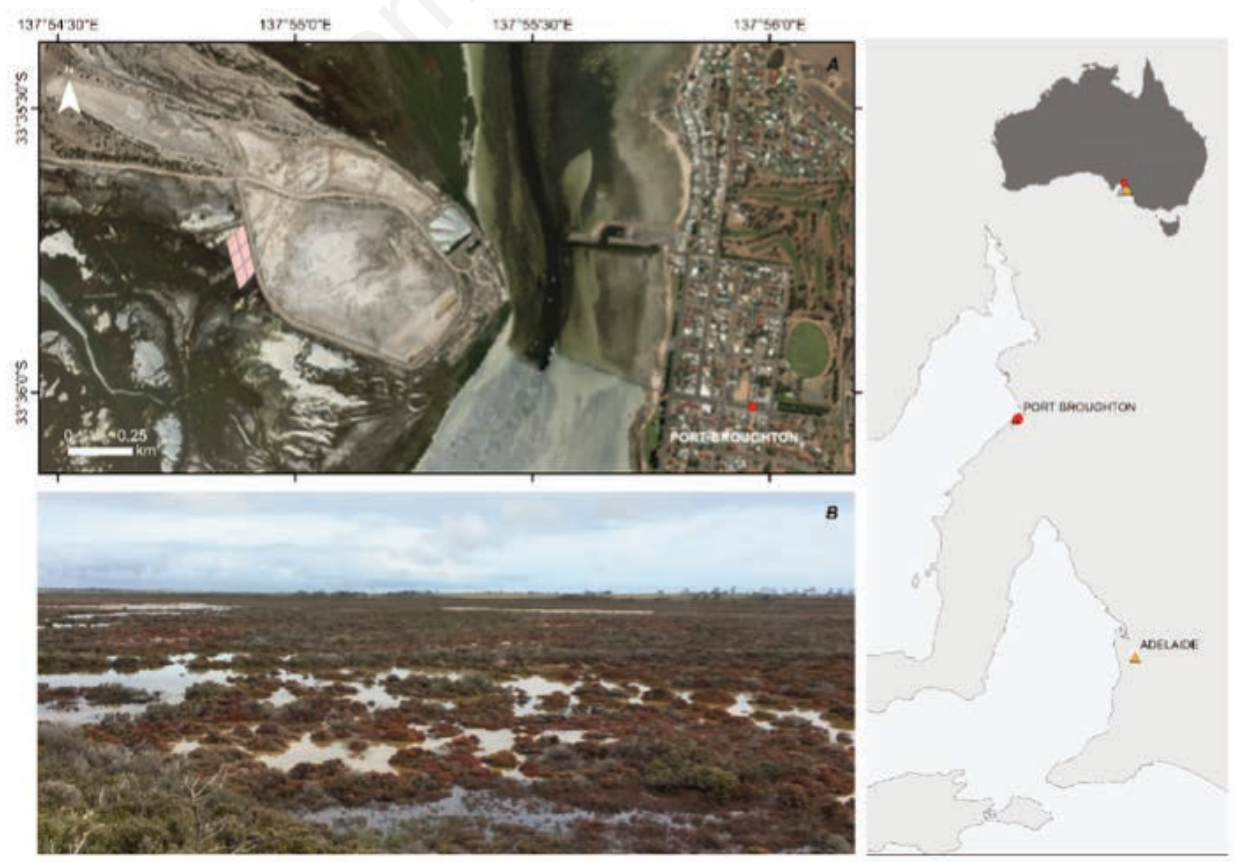

Figure 1. A) Field study at Port Broughton. The ground survey area was approximately 1.7 ha, divided into six 50 x $65 \mathrm{~m}$ quadrats shown in pink. B) Environmental conditions on the day of survey, where high tides and rain the day prior formed small temporary pools that may be suitable for mosquito breeding. 
classes that may be present in the NIR imagery. The 71 field samples were used to assess the accuracy of the resultant maps using an error matrix and commonly-used measures of accuracy including overall accuracy, Producer's accuracy, User's accuracy and Cohen's Kappa coefficient.

\section{Results}

\section{Water Depth}

The two-way ANOVA showed a significant statistical difference between NIR reflectance of the inundated and non-inundated treatments $(p=0.01,<0.05)$, as well as between the different water depths $(p=0.01)$. It also determined a significant interaction between the status of inundation and water depth $(p=0.02)$, suggesting possible confounding factors (Figure 2).

We then eliminated the variable of minimal depth $(5 \mathrm{~cm})$ from the linear model and ran a second two-way ANOVA. This second analysis showed no significant interaction between inundation status and water depth $(\mathrm{p}=0.16)$, suggesting that there were confounding effects at water depths below $10 \mathrm{~cm}$ where there was likely confusion between water and substrate. Moreover, the water depth trials showed a clear difference in reflectance, with the mean of all non-inundated treatments having higher reflectances than the inundated at all water depths, all below a mean reflectance of 0.2 . This threshold was thus selected for the subsequent drone image field trials to define areas of shallow inundation.

\section{Vegetation Cover}

There was a significant statistical difference between percentage vegetation cover and NIR reflectance $(p<0.01)$, indicating that reflectance is strongly attributed to vegetation cover (Figure 2). There was no statistical significance between inundation status, and no interaction between inundation status and cover. There was however an anomaly at $70 \%$ vegetation cover. This was found to be due to a mis-calibration, where the maximum percentage reflectance recorded for this group was much higher than that of others, thereby affecting its reflectance values (see Appendix). Regardless, the strong positive effect of vegetation cover on NIR reflectance, and the lack of statistical significance associated with inundation status $(\mathrm{p}=0.24)$, as well as between the interaction between inundation and vegetation cover $(p=0.75)$, suggests that vegetation cover even in small amounts, can affect reflectance. We thus expected possible misclassifications in the subsequent field trials, where the sub-class of 'water under vegetation' may be classified as 'vegetation' rather than 'water'.

\section{Classification accuracy}

The classified map delineating shallow inundation below a NIR reflectance threshold of 0.2 had an overall mapping accuracy of $66.2 \%$ (Table 2; Figure 3). The Producer's accuracy, which illustrates how accurately the samples have been classified in the image, was $69.6 \%$ for the inundated samples, and $64.6 \%$ for the non-inundated samples. The User's accuracy, the proportion of each map class that is consistent with ground records, was $48.5 \%$ for inundated samples, and $81.6 \%$ for non-inundated samples. Hence, this signifies a high error of commission (51.5\%) i.e. an overclassification, likely due to a proportion of non-inundated areas on the ground identified as inundated on the map. The Kappa coefficient of 0.32 indicated overall poor agreement between the classified image and field observations.

The classified map delineating shallow inundation taking into account vegetation cover had an overall mapping accuracy of $80.3 \%$, a higher classification accuracy than the mapping based on NIR density slicing alone (Table 2; Figure 3). The Producer's accuracy was $43.5 \%$ for the inundated samples, and $97.9 \%$ for the noninundated samples. The User's accuracy was $90.9 \%$ for inundated samples, and $78.3 \%$ for non-inundated samples. The Kappa coefficient for this confusion matrix is 0.5 , indicating a good agreement between the classified image and the field observations.
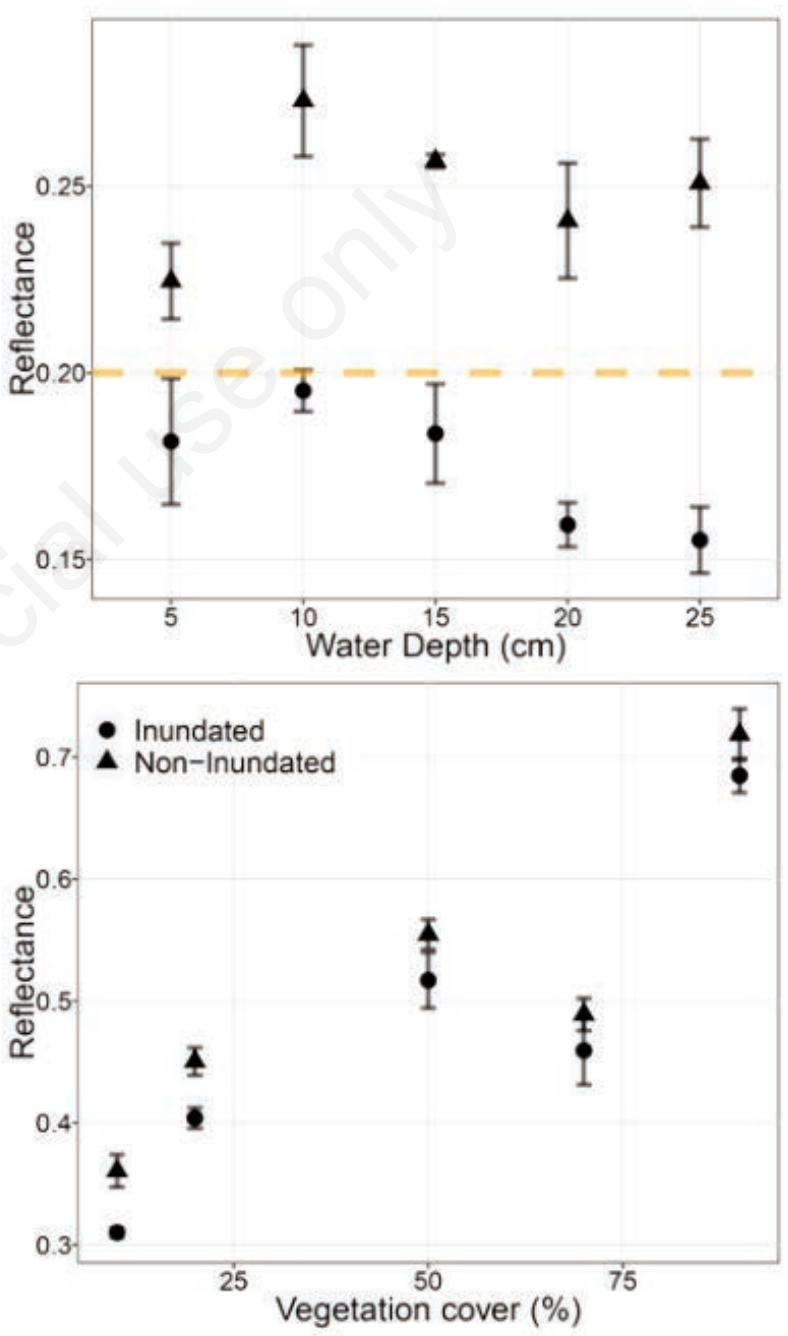

Figure 2. The mean reflectances of the three Near-Infrared (NIR) images from each inundated and non-inundated treatments were measured at $5 \mathrm{~cm}, 10 \mathrm{~cm}, 15 \mathrm{~cm}, 20 \mathrm{~cm}$ and $25 \mathrm{~cm}$ for the water depth laboratory trials (above), with the error bars indicating one standard deviation. All of the non-inundated treatments have higher reflectances than inundated treatments at all water depths, with the threshold being a mean reflectance of 0.2 (orange dashed line). The mean reflectances of the three NIR images from each inundated and non-inundated treatments for the vegetation cover trials were also measured, at $10 \%, 20 \%, 50 \%, 70 \%$ and $90 \%$ (below), with the error bars indicating one standard deviation. We find that vegetation cover has a strong positive effect on NIR reflectance. 
The reduction in Producer's accuracy indicates the higher likelihood of a sample being classified as another class on the map despite it being inundated on the ground. This further suggests the possibility of vegetation cover having an influence on the accuracy of classifications, i.e. the sub-class of 'water under vegetation' likely being classified as 'vegetation' rather than 'water', for example.

Table 2. Error matrices for shallow inundation classification from the Near-Infrared (NIR ${ }^{\dagger}$ ) map indicating an overall accuracy of $66.2 \%$ and near-infrared-normalised difference vegetation index (NIR-NDVI ${ }^{\ddagger}$ ) map indicating an overall accuracy of $80.3 \%$.

\begin{tabular}{|c|c|c|c|c|c|}
\hline & & $\begin{array}{l}\text { Field } \\
\text { Inundated }\end{array}$ & Non-Inundated & Total & User's Accuracy \\
\hline \multirow{4}{*}{ 兴 } & Inundated & 16 & 17 & 33 & $48.5 \%$ \\
\hline & Non-Inundated & 7 & 31 & 38 & $81.6 \%$ \\
\hline & Total & 23 & 48 & 71 & \\
\hline & Producer's Accuracy & $69.6 \%$ & $64.6 \%$ & & Overall Accuracy $66.2 \%$ \\
\hline \multicolumn{2}{|c|}{ NIR-NDVIE: } & $\begin{array}{l}\text { Field } \\
\text { Inundated }\end{array}$ & Non-Inundated & Total & User's Accuracy \\
\hline \multirow{4}{*}{ 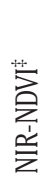 } & Inundated & 10 & 1 & 11 & $90.9 \%$ \\
\hline & Non-Inundated & 13 & 47 & 60 & $78.3 \%$ \\
\hline & Total & 23 & 48 & 71 & \\
\hline & Producer's Accuracy & $43.5 \%$ & $97.9 \%$ & & Overall Accuracy $80.3 \%$ \\
\hline
\end{tabular}
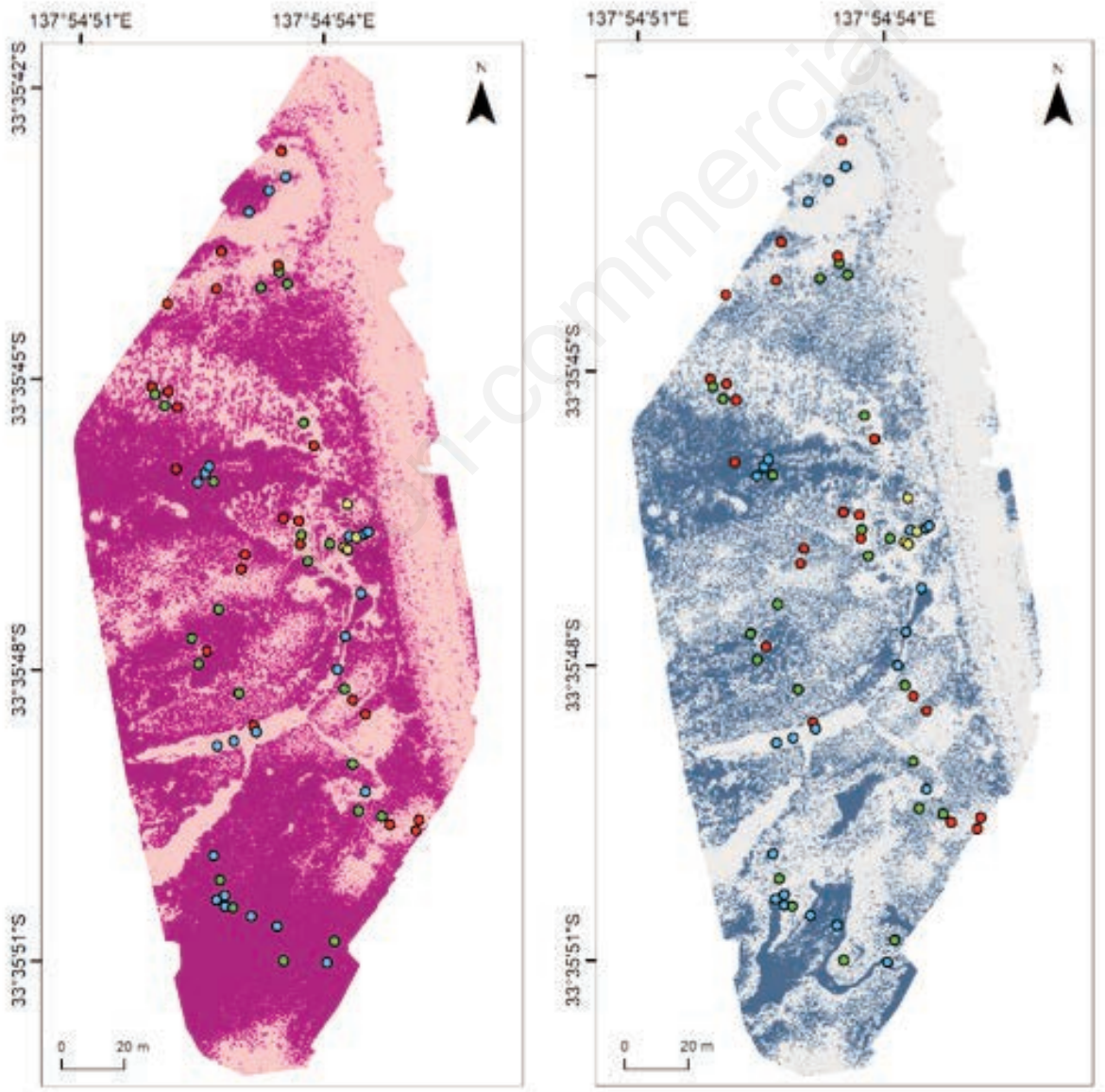

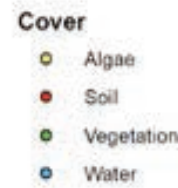

NIR† Inundation Classification

Status

ए Non-inundated

inundated

NIR-NDVI $¥$ Inundation Classification

Status

$\square$ Non-inundated

Inundated

Coordinate System: GDA 1994 MGA Zone 53 Projection: Transverse Mercator Datum: GDA 1994 Units: Meter

Figure 3. Near-Infrared (NIR) classified map identifying shallow inundation based on the density slice threshold at 0.2 reflectance (left), and based on the density slice threshold of 0.2 NIR reflectance and an Normalised Difference Vegetation Index threshold of 0.4 (right), with the location of the 71 survey plots classed in situ as algae (in yellow), soil (red), vegetation (green) and water (blue). 


\section{Water Sub-class Comparisons}

Of the seventy-one sample points, twenty-three were classified as 'water'. It was further observed in both maps that the misclassification of cover types was strongly associated with their particular sub-classes and water depth. The addition of water depth information taken in the field clarified the classifications (Table 3 ).

The sub-class 'water under vegetation' was mainly classified as inundated in the NIR classified map. While this is an apparently correct classification, the NIR imagery revealed self-shadowing of the southern sides of many vegetation clumps upon closer inspection, resulting in low reflectance values and meeting the requisites for an inundation classification.

Nonetheless, 'water under dead vegetation' and 'algae under water' were both correctly classified under the broad cover type 'water', while the sub-class 'water under vegetation was mainly misclassified as non-inundated. The sub-class for 'open water' was divided into three categories; depth shallower than $5 \mathrm{~cm}$, depths equal to and greater than $5 \mathrm{~cm}$ and less than $10 \mathrm{~cm}$, and depths equal to and greater than $10 \mathrm{~cm}$. This sub-division revealed that most samples of deeper waters $(\geq 5 \mathrm{~cm})$ were correctly classified as inundated - with the one misclassification likely to be due to the presence of suspended algae - while those of shallower water $(<5$ $\mathrm{cm}$ ) were mostly misclassified as non-inundated.

\section{Discussion}

Through laboratory and field trials, we have determined that a NIR reflectance threshold of equal or greater than 0.2 together with an NDVI equal and greater than 0.4 was sufficient to determine shallow inundation that may be suitable for mosquito breeding, with a high classification accuracy of $80.3 \%$. Moreover, the minimum depth for confident discrimination of inundation and noninundation through NIR imagery was determined to be $10 \mathrm{~cm}$, though sub-class comparison suggests that it may even be possible to distinguish inundation as shallow as $5 \mathrm{~cm}$. The trials also revealed that even small amounts of overhanging vegetation can prevent the confident detection of inundation, as shown in the misclassifications of samples in the sub-class 'water under vegetation'. This study thus provided an understanding of the capabilities of drones and the MicaSense multispectral camera to determine shallow inundation, using a simple image classification approach that could readily be adopted for rapid mitigation action.

\section{Sensor response to inundation, water depth and vegetation}

The delineation of water from other classes was illustrated in the laboratory results, where the non-inundated samples had gen- erally higher reflectance than the inundated samples, and were distinguishable from one another at the 0.2 reflectance threshold in the NIR imagery.

Reflectance was expected to decrease with increasing water depth due to the reduction in reflectance from the substrate (Lyzenga, 1981; Zeng et al., 2017). However, in our study, the increase in water depth did not have any statistical effect on reflectance after the removal of the $5 \mathrm{~cm}$ variable. This is likely due to the very shallow range of the water depths tested i.e. between $5 \mathrm{~cm}$ and $25 \mathrm{~cm}$, as well as the small intervals between variables i.e. at $5 \mathrm{~cm}$ intervals, unlike the study by Zeng et al. (2017), which observed depths from $50 \mathrm{~cm}$ to a lake bottom.

Furthermore, the confounding effects observed from the laboratory trials suggests that the sensor was unable to confidently discriminate between inundation and non-inundation at depths less than $10 \mathrm{~cm}$. This is likely due to the shallow depths, where the NIR reflectance from the substrate may have outweighed the absorption of water, leading to confusion in classification. This was further observed in subsequent classifications where a proportion of inundated field samples were identified as non-inundated on the map, with all samples having depths of less than $10 \mathrm{~cm}$.

Similarly, the lack of statistical significance of NIR reflectance associated with inundation status, as well as interaction between inundation and vegetation cover was likely a result of vegetation reflectance considerably outweighing the NIR absorption from water, which was characteristic of their inherent spectral properties (Knipling, 1970).

\section{Field mapping and classification}

Generally, both maps correctly classified algae and soil cover types as non-inundated. This was expected and likely due to their higher reflectances in the NIR wavelengths, which allocated them in the upper threshold of the density slice, delineating them from inundated habitats. 'Algae under water' was classified as inundated in both maps, despite having photosynthetic activity, as the NDVI of the algae was $0.34(<0.4)$. Dead vegetation, including the sub-class 'water under dead vegetation', was classified as expected as inundated, as dead vegetation no longer contains the cellular structures for internal scattering of radiation resulting in lower NIR reflectance (Knipling, 1970).

This however, was a source of commission error for the class 'dead vegetation' and affected the overall mapping accuracy of both maps. In addition, visual inspection showed that the class 'open water' frequently included suspended algae in assessments. This resulted in higher NIR reflectances due to its photosynthetic capabilities, and thus was classified as non-inundated instead, affecting mapping accuracies. One of the bigger sources of errors was the misclassification of 'open water' as non-inundated.

Table 3. Sub-class comparisons within the cover type 'water' in relation to the near-infrared (NIR $\dagger$ ) classified map and the and nearinfrared-normalised difference vegetation index (NIR-NDVI ) classification. Values are counts of field sample points that are classified based on the rules for production of each map.

\begin{tabular}{|c|c|c|c|c|c|c|c|c|}
\hline Map & Status & $\begin{array}{l}\text { Open Water } \\
\text { (<5 cm) }\end{array}$ & $\begin{array}{c}\text { Open Water } \\
(5 \leq x<10 \mathrm{~cm})\end{array}$ & $\begin{array}{l}\text { Open Water } \\
(\geq 10 \mathrm{~cm})\end{array}$ & $\begin{array}{l}\text { Water under } \\
\text { Vegetation }\end{array}$ & $\begin{array}{l}\text { Water under dead } \\
\text { Vegetation }\end{array}$ & $\begin{array}{l}\text { Algae Under } \\
\text { Water }\end{array}$ & Total \\
\hline $\mathrm{NIR}^{\dagger}$ & $\begin{array}{l}\text { Inundated } \\
\text { Non-Inundated }\end{array}$ & $\begin{array}{l}1 \\
5\end{array}$ & $\begin{array}{l}5 \\
0\end{array}$ & $\begin{array}{l}4 \\
0\end{array}$ & $\begin{array}{l}5 \\
1\end{array}$ & $\begin{array}{l}1 \\
0\end{array}$ & $\begin{array}{l}1 \\
0\end{array}$ & $\begin{array}{l}17 \\
6\end{array}$ \\
\hline NIR-NDVI & $\begin{array}{l}\text { Inundated } \\
\text { Non-Inundated }\end{array}$ & $\begin{array}{l}0 \\
6\end{array}$ & $\begin{array}{l}4 \\
1\end{array}$ & $\begin{array}{l}4 \\
0\end{array}$ & $\begin{array}{l}0 \\
6\end{array}$ & $\begin{array}{l}1 \\
0\end{array}$ & $\begin{array}{l}1 \\
0\end{array}$ & $\begin{array}{l}10 \\
13\end{array}$ \\
\hline
\end{tabular}


Through the unpacking of the water sub-class comparisons (Table 3), this error was revealed to be the confusion between the 'soil' class with 'water' in the imagery, where, as with the laboratory trials, the NIR reflectance outweighs the absorption of water of depths shallower than $10 \mathrm{~cm}$, characterising more soil features in the classified map . Nevertheless, the sub-class comparison also suggests that it may even be possible to distinguish inundation as shallow as $5 \mathrm{~cm}$, where 5 out of 5 sites, and 4 out of 5 sites were correctly classified as inundated in both the classified NIR and the NIRNDVI maps respectively.

The sub-class 'water under vegetation' was classified as noninundated in the NIR-NDVI map, despite the initial apparent correct classification in the NIR map due to shadowing. Incorporating the NDVI mask and setting the vegetation threshold to be equal or greater than 0.4 instead allocated the sub-class into the upper threshold of the density slice. This further substantiates the findings from the laboratory trials i.e. that vegetation cover has a very strong positive effect on reflectance, and can greatly affect the accuracy of classifications.

An experimental limitation would be that the number of samples taken within the study site (71 sample plots), as well as the size of the study site itself (approximately $1.7 \mathrm{ha}$ ) was small, hence, the maps may not strongly represent the broader landscape. Further trials in a wider range of environments are recommended to test the broader applicability of our findings.

\section{Significance to Mosquito Mitigation Efforts}

Together with the knowledge of the mosquitoes' local ecology, the acquisition of real-time high resolution imagery using low-cost drones can better target potential breeding sites for effective mitigation action. A. vigilax and A. camptorhynchus depend on different environmental conditions to breed successfully, despite both species being found in and close to saltmarsh (Johnston et al., 2014). A. camptorhynchus tend to breed in cooler months (between May and September), utilising small pools that are mainly recharged by rainfall and groundwater. $A$. vigilax on the other hand, tend to breed in the warmer months (between December and March) and rely on small tidal filled pools isolated from predators for larvae development (Kokkinn et al., 2009; Williams et al., 2009). Compared to using Landsat imagery for example, the use of drones immensely improves the spatial resolution (from $30 \mathrm{~m}$ to sub-decimetre pixel resolution depending on the sensor used and flight altitude) and enables users to obtain imagery whenever required and as frequently as possible for better, targeted mitigation. The multispectral sensor further complements this by allowing delineation of small, shallow pools of water that both $A$. vigilax and A. camptorhynchus is known to breed in through its spectral response in the NIR wavelengths.

Although our main focus was on South Australia's saltmarsh species, mosquito breeding has been reported to occur in even shallower waters (less than $4 \mathrm{~cm}$ ) (Bennelongia Pty Ltd, 2012), with species such as Aedes notoscriptus being well known container breeders (Williams and Rau, 2011). The inability of the sensor to discriminate between inundated and non-inundated conditions at water depths shallower than $10 \mathrm{~cm}$, as well as its inability to determine areas of 'water under vegetation' thus highlights the limitation of using NIR sensors to identify potential breeding sites. Authorities across Australia, nonetheless, advise against creating wetlands with dense vegetation and of depths less than $60 \mathrm{~cm}$, such that predators are able to feed on mosquito larvae (Government of South Australia, 2006; Queensland Government, 2002).
Nonetheless, while our classification methods may have demonstrated the potential to effectively map areas of inundation, even with a map with User's Accuracy of $90.9 \%$, uncertainties persist and have to be taken into consideration in any mitigation action. A user relying on a map that overclassifies inundated areas for larvicide application could lead to scarce resources being wasted on non-target areas. On the other hand, a user relying on an underclassified map could miss areas of potential mosquito breeding. Hence, decision-makers have to exercise caution when using such classification maps and consider the cost-effectiveness of mitigation prior to action.

Our study was not designed to inform on whether such sites were productive i.e. having mosquitoes in their immature stage present in that point in time, whereas the study by CarrascoEscobar et al. (2019) positively identified bodies of water that host mosquito larvae using multispectral drone imagery in Amazonian Peru for more targeted mitigation. Together with our findings in regards to NIR response to water and water depths, along with those of Hardy et al. (2017), there is now better understanding of the possibility and practicality of using drones and the multitude of sensors towards efficient and effective mosquito mitigation.

\section{Future Research}

Drones and their sensors are becoming more accessible and inexpensive. The rapid advancements in technology - improvements in battery life, integrated sensors (in optical, multispectral, thermal or hyperspectral wavelengths) and GPS, and better processing software - have allowed for the effective monitoring of potential mosquito breeding habitats, and possibly for active mitigation through drone dispersal of larvicide to identified pools (Huang et al., 2009). Though not yet commercial, such advancements, along with the development of newer technologies and approaches such as the use of computer vision are encouraging and could be used towards the mitigation of mosquito-borne diseases in the near future (Allan et al., 2018; Chen et al., 2014; Mehra et al., 2016).

\section{Conclusion}

Mosquito-borne diseases can seriously impact human productivity and quality of life, with potentially significant flow-on impacts to economies. Current methods for identifying potential mosquito breeding habitats in South Australia are slow, labourintensive and expensive due to the need for ground surveys in areas that are hard to access. Satellite remote sensing has shown potential in mapping likely areas of breeding, though at regional scales. Drones and their available sensors thus fill the operational gaps with their ability to vary spatial resolutions and acquire timely imagery. This study thus provided a better understanding of the responses of the MicaSense RedEdge multispectral sensor to various environmental variables, and delineated shallow inundation with high mapping accuracy through simple remote sensing classification techniques. The results have proven encouraging, though potential limitations were flagged. With rapid advancements in drone and sensor technology, there is great potential for further refinement for mosquito disease mitigation and monitoring through passive or active methods, thus directly tackling this global public health problem. 


\section{References}

Allan BM, Nimmo DG, Ierodiaconou D, Van der Wal J, Koh LP, Ritchie EG, 2018. Futurecasting ecological research: the rise of technoecology. Ecosphere 9.

Bennelongia Pty Ltd, 2012. Field Survey and Site Assessment of Mosquitoes at Kintyre Camp in June and December 2011. Available from: https://www.camecoaustralia.com/uploads /downloads/ermp_documents/Appendix_V-Mosquito_Site_ Assessment_Report.pdf

Bergquist R, Amer S, 2019. Good things come in small packages: New trends in acquisition of remotely-sensed data. Geospat Health 14:781. doi: 10.4081/gh.2019.781.

Bi P, Hiller JE, Cameron AS, Zhang Y, Givney R, 2009. Climate variability and Ross River virus infections in Riverland, South Australia, 1992-2004. Epidemiol Infect 137:1486-93.

Bureau of Meteorology, 2019. Climate statistics for Australian locations: Snowtown (Rayville Park). Available from: http://www.bom.gov.au/climate/averages/tables/cw_021133.shtml

Carrasco-Escobar G, Manrique E, Ruiz-Cabrejos J, Saavedra M, Alava F, Bickersmith S, Prussing C, Vinetz JM, Conn JE, Moreno M, 2019. High-accuracy detection of malaria vector larval habitats using drone-based multispectral imagery. PLoS neglected tropical diseases 13:e007105

Chabot D, Dillon C, Shemrock A, Weissflog N, Sager E, 2018. An object-based image analysis workflow for monitoring shallowwater aquatic vegetation in multispectral drone imagery. ISPRS International Journal of Geo-Information 7:294.

Chen Y, Shioi H, Montesinos CF, Koh LP, Wich S, Krause A, 2014. Active Detection via Adaptive Submodularity. Proceedings of the 31st International Confrence on Machine Learning, Beijing, China 32.

Clennon JA, Kamanga A, Musapa M, Shiff C, Glass GE, 2010. Identifying malaria vector breeding habitats with remote sensing data and terrain-based landscape indices in Zambia. Int $\mathbf{J}$ Health Geographics 9:1-13.

Dale P, Hulsman K, Harrison D, Congdon, B, 1986. Distribution of the immature stages of Aedes vigilax on a coastal salt-marsh in southeast Queensland. Australian J Ecol 11:269-78.

Dambach P, Machault V, Lacaux J, Vignolles C, Sie A, Sauerborn R, 2012. Utilisation of combined remote sensing techniques to detect environmental variables influencing malaria vector densities in rural West Africa. Int J Health Geographics 11:1-12

ESRI, 2015. ArcGIS 10.3.1. Available from: http://www.esri.com/software/arcgis/arcgis-for-desktop

Fernandez-Guisuraga JM, Sanz-Ablanedo E, Suarez-Seoane S, Calvo L, 2018. Using Unmanned Aerial Vehicles in Postfire Vegetation Survey Campaigns through Large and Heterogeneous Areas: Opportunities and Challenges. Sensors (Basel) 18.

Government of South Australia, 2006. South Australian Integrated Mosquito Management Resource Package 2006: An Informative Guide for Mosquito Management Practitioners.

Goward SN, Huemmrich KF, Waring RH, 1994. Visible-near infrared spectral reflectance of landscape components in Western Oregon. Remote Sens Environ 47:190-203.

Hardy A, Makame M, Cross D, Majambere S, Msellem M, 2017. Using low-cost drones to map malaria vector habitats. Parasit Vectors 10:29.

Hassan AN, Nogoumy NE, Kassem HA, 2013. Characterization of landscape features associated with mosquito breeding in urban Cairo using remote sensing. Egyptian J Remote Sensing Space Sci 16:63-9.

Huang Y, Hoffman WC, Lan Y, Wu W, Fritz BK, 2009. Development of a spray system for an unmanned aerial vehicle platform. Am Soc Agricultural and Biological Engineers 25:803-9.

Hugh-Jones M, 1989. Applications of remote sensing to the identification of habitats of parasites and disease vectors. Parasitology Today $5: 244-51$.

Johnston E, Weinstein P, Slaney D, Flies A, Fricker S, Williams C, 2014. Mosquito communities with trap height and urban-rural gradient in Adelaide, South Australia: implications for disease vector surveillance. J Vector Ecology 39:48-55.

Knipling E, 1970. Physical and physiological basis for the reflectance of visible and near-infrared radiation from vegetation. Remote Sens Environ 1:155-9.

Kokkinn M, Duval D, Williams C, 2009. Modelling the ecology of the coastal mosquitoes Aedes vigilax and Aedes camptorhynchus at Port Pirie, South Australia. Med Vet Entomol 23:85-91.

Lyzenga DR, 1981. Remote sensing of bottom reflectance and water attenuation parameters in shallow water using aircraft and Landsat data. Int J Remote Sensing 2:71-82.

Mackenzie JS, Smith DW, 1996. Mosquito-borne viruses and epidemic polyarthritis. Med J Australia 164:90-3.

Mehra M, Bagri A, Jiang X, Ortiz J, 2016. Image Analysis for Identifying Mosquito Breeding Grounds. Paper presented at the 2016 IEEE International Conference on Sensing, Communication and Networking (SECON Workshops).

MicaSense, 2015. MicaSense RedEdge 3 Multispectral Camera User Manual. Seattle, WA.

Paine D, Kiser J, 2003. Aerial Photography and Image Interpretation. USA: John Wiley and Sons, Inc.

Paredes JA, Gonzalez J, Saito C, Flores A, 2017. Multispectral imaging system with UAV integration capabilites for crop analysis. Paper presented at the 2017 First IEEE International Symposium of Geoscience and Remote Sensing (GRSS-CHILE).

Queensland Government, 2002. Guidelines to minimize mosquito and biting midge problems in new development areas. Public Health Services, Queensland Government, Queensland Health, 22.

Rowbottom R, Carver S, Barmuta LA, Weinstein P, Allen GR, 2017. Mosquito distribution in a saltmarsh: determinants of eggs in a variable environment. J Vector Ecol 42:161-70.

Russell RC 1998. Mosquito-borne arboviruses in Australia: the current scene and implications of climate change for human health. Int $\mathrm{J}$ Parasitol 28:955-69.

Smith GM, Milton EJ, 1999. The use of the empirical line method to calibrate remotely sensed data to reflectance. Int J Remote Sensing 20:2653-62.

Williams CR, Rau G, 2011. Growth and development performance of the ubiquitous urban mosquito Aedes notoscriptus (Diptera: Culicidae) in Australia varies with water type and temperature. Australian J Entomol 50:195-9.

Williams CR, Williams SR, Nicholson J, Little SM, Riordan J, Fricker SR, Kokkinn MJ, 2009. Diversity and seasonal succession of coastal mosquitoes (Diptera: Culicidae) in the northern Adelaide region of South Australia. Australian J Entomol 48:107-12.

Zeng C, Richardson M, King DJ, 2017. The impacts of environmental variables on water reflectance measured using a lightweight unmanned aerial vehicle (UAV)-based spectrometer system. ISPRS J Photogrammetry Remote Sensing 130:217-30. 